\title{
2 Differential expression of the brassinosteroid receptor-encoding BRI1 gene in Arabidopsis
}

4 Lidia Hategan • Blanka Godza - Laszlo Kozma-Bognar •

5 Gerard J. Bishop • Miklos Szekeres

6 Received: 7 November 2013 / Accepted: 15 January 2014

7 C) Springer-Verlag Berlin Heidelberg 2014

8 Abstract Brassinosteroid (BR)-regulated growth and 9 development in Arabidopsis depends on BRASSINOS10 TEROID INSENSITIVE 1 (BRI1), the BR receptor that 11 is responsible for initiating the events of BR signalling. 12 We analysed the temporal and spatial regulation of BRI1 13 expression using stable transgenic lines that carried BRII 14 promoter:reporter fusions. In both seedlings and mature plants the tissues undergoing elongation or differentiation showed elevated BRII gene activity, and it could be demonstrated that in the hypocotyl this was accompanied by accumulation of the BRII transcript and its receptor protein product. In seedlings the BRII promoter was also found to be under diurnal regulation, determined primarily by light repression and a superimposed circadian control. To determine the functional importance of transcriptional regulation we complemented the severely BR insensitive bri1-101 mutant with a BRI1-luciferase fusion construct that was driven by promoters with contrasting specificities. Whereas the BRII promoter-driven transgene fully restored

L. Hategan and B. Godza contributed equally to this work.

Electronic supplementary material The online version of this article (doi:10.1007/s00425-014-2031-4) contains supplementary material, which is available to authorized users.

L. Hategan · B. Godza $\cdot$ L. Kozma-Bognar $\cdot$ M. Szekeres $(\triangle)$ Institute of Plant Biology, Biological Research Centre of the Hungarian Academy of Sciences, 6726 Szeged, Hungary e-mail: szekeres@brc.hu

G. J. Bishop

Division of Biology, Imperial College London,

London SW7 1AZ, UK

Present Address:

G. J. Bishop

East Malling Research, Kent ME19 6BJ, UK the wild phenotype, expression from the photosynthesisassociated $C A B 3$ and the vasculature-specific $S U C 2$ and $A T H B 8$ promoters resulted in plants with varying morphogenic defects. Our results reveal complex differential regulation of BRII expression, and suggest that by influencing the distribution and abundance of the receptor this regulation can enhance or attenuate BR signalling.

Keywords Ectopic expression - Hormone susceptibility . Phytohormone $\cdot$ Reporter gene

$\begin{array}{ll}\text { Abbreviations } \\ \text { BR } & \text { Brassinosteroid } \\ \text { BL } & \text { Brassinolide } \\ \text { CS } & \text { Castasterone } \\ \text { DD } & \text { Continuous dark } \\ \text { LD } & \text { Light-dark cycles } \\ \text { LL } & \text { Continuous light } \\ \text { DAG } & \text { Days after germination } \\ \text { LUC } & \text { Firefly luciferase } \\ \text { GUS } & \beta \text {-Glucuronidase }\end{array}$

\section{Introduction}

Brassinosteroids (BRs) are polyhydroxylated steroid hormones that control plant development from germination to seed production (Clouse and Sasse 1998; Haubrick et al. 2006). The biologically active BRs castasterone (CS) and brassinolide (BL) are perceived by the plasma membrane-localized leucine-rich repeat receptor-like kinase BRASSINOSTEROID INSENSITIVE 1 (BRI1) (Li and Chory 1997), which then initiates a phosphorylation/dephosphorylation-based signalling cascade that controls the transcriptional activity of BR-responsive genes.

\begin{tabular}{|l|ll|}
\hline Journal : Large 425 & Dispatch : 27-1-2014 & Pages : 13 \\
Article No : 2031 & $\square$ LE & $\square$ TYPESET \\
MS Code : PLAA-D-13-00697 & $\square \quad C P$ & $\square$ DISK \\
\hline
\end{tabular}


This intracellular process, which has been well characterized in Arabidopsis, is mediated by BRASSINOSTEROID INSENSITIVE 2 (BIN2), a GSK3/SHAGGY-like kinase, and its downstream targets the BRASSINAZOLE RESISTANT transcription factors BZR1 and BZR2/BES1 (for review see: Kim and Wang 2010).

The BRI1 receptor is a key component of BR signalling. Binding of the active hormone by the extracellular domain (Kinoshita et al. 2005) results in activation of the intracellular kinase domain and leads to its dissociation from the BRI1 KINASE INHIBITOR 1 (BKI1) (Wang and Chory 2006). Once freed from BKI1, BRI1 interacts with its somatic embryogenesis receptor kinase-type co-receptor BRI1-ASSOCIATED KINASE 1 (BAK1/SERK3) (Li et al. 2002; Nam and Li 2002; Russinova et al. 2004) and, following transphosphorylation steps, the activated receptor complex initiates the intracellular events of BR signalling (Wang et al. 2008).

Severe bril mutants lacking functional BR receptors show serious developmental defects, such as severe dwarfness, irregular vascularization, and male sterility (Clouse et al. 1996; Montoya et al. 2002), which have also been observed in BR-deficient plants (Szekeres et al. 1996; Li et al. 1996; Bishop et al. 1996). This indicates the essential role of BRI1 in BR perception. Whereas in Arabidopsis, two of its homologues, the closely related BRI1-LIKE 1 and 3 (BRL1, BRL3), are also functional BR receptors (CañoDelgado et al. 2004; Zhou et al. 2004), inactivation of either or both of these vascularly expressed functions does not lead to visible phenotypic effects (Caño-Delgado et al. 2004).

Unlike other phytohormones, BRs are not subject to active transport (Symons and Reid 2004; Montoya et al. 2005), therefore, the concentration gradient required for eliciting differential responses is formed primarily by regulated local biosynthesis and deactivation of the hormone (Montoya et al. 2005; Nomura et al. 2007; Symons et al. 2012). Variation of BR levels is controlled by homeostatic feedback regulation of the biosynthetic genes (Bancos et al. 2002; Tanaka et al. 2005) and feed-forward regulation of the deactivating genes (Choe et al. 2001; Vert et al. 2008), which limit the concentration range available for hormonal control. This, together with earlier indications of light-regulated BR responsiveness (Turk et al. 2003; Yang et al. 2005; Bancos et al. 2006), suggested that plants may modulate BR signalling via developmental and spatial regulation of their sensitivity to the hormone.

BRI1 directly controls BR responses by interacting with the hormone and initiating the signalling process. Whereas downstream signalling components can influence the output at the transcriptional level, the function and stability of these internal regulators are also modulated by the active receptor complexes ( $\mathrm{Li}$ and Jin 2007; Wang et al. 2012a). A confocal microscopy-based study revealed considerable cell typespecific differences in the surface density of BRI1, implying that the intensity of BR signalling correlates with the abundance of the receptor (van Esse et al. 2011). This was shown to depend on the endocytotic internalization of BRI1, which is then followed by its degradation or recycling to the cell surface (Russinova et al. 2004; Geldner et al. 2007). Receptor availability can also be adjusted via differential expression of BRI1, but earlier results indicated that this is not spatially regulated (Friedrichsen et al. 2000), or that in mature Arabidopsis there are only minor differences between organ-specific levels of the BRII transcript (Li and Chory 1997; Shimada et al. 2003). On the other hand, microarray analyses revealed that BRII mRNA accumulation is negatively regulated by BRs (Goda et al. 2002), and our pilot experiments using transgenic seedlings that carried promoter-reporter fusions also indicated differential BRII expression.

Our aim was to find out how BRII expression is regulated at the transcriptional level, and to what extent this control influences BR-dependent development in Arabidopsis. We used transgenic lines carrying promoterreporter fusions to determine the temporal and spatial patterns of BRII gene activity. To clarify the developmental importance of the observed differential regulation, we generated transgenic lines that express BRII ectopically, under the control of well-characterized tissue-specific promoters. Our results reveal that proper morphogenesis requires precise regulation of BRII expression and localization.

\section{Materials and methods}

Plant material and growth conditions

All experiments were carried out using wild-type Arabidopsis thaliana (L.) Heynh. ecotype Columbia (Col-0) (Nottingham Arabidopsis Stock Centre, UK), and the severely BR insensitive bri1-101/binl-1 missense mutant ( $\mathrm{Li}$ and Chory 1997) of Col-0 background (gift from Jianming Li, University of Michigan, USA). For in vitro cultures, surface-sterilized seeds were spread over Murashige and Skoog medium supplemented with $1 \%$ sucrose and $0.2 \%$ Phytagel (Sigma, St. Louis, MO). Seedlings were germinated and grown at $22{ }^{\circ} \mathrm{C}$ in a controlled-environment chamber (SANYO Electronic, Tokyo, Japan) under alternating regimes of 12-h fluorescent white light (photon flux density 50-60 $\mu \mathrm{mol} \mathrm{m}^{-2} \mathrm{~s}^{-1}$ ) and 12-h dark (LD). Except illumination, conditions during continuous light (LL) and dark (DD) treatments were identical with those of the corresponding phases of LD. For maintenance and phenotypic characterization, plants were grown in temperature-controlled (20$\left.22{ }^{\circ} \mathrm{C}\right)$ greenhouse. Following 4 to 5 weeks of vegetative growth under short-day conditions $(8 \mathrm{~h} \mathrm{~L} / 16 \mathrm{~h} \mathrm{D})$, the plants were brought to flowering and seed production under longday illumination cycles (16 h L/8 h D).

\begin{tabular}{llll|} 
Journal : Large 425 & Dispatch : 27-1-2014 & Pages : 13 \\
Article No : 2031 & $\square \quad$ LE & $\square$ TYPESET \\
MS Code : PLAA-D-13-00697 & $\square \quad C P$ & $\square$ DISK \\
\hline
\end{tabular}


Table 1 Gene-specific oligonucleotide primers

\begin{tabular}{lll}
\hline Gene & Primer & Sequence $\left(5^{\prime} \rightarrow 3^{\prime}\right)$ \\
\hline ATHB8 & ATHB8pr-F & $\begin{array}{l}\text { TTAAAATGGCCTGCAACTGTACGGATA } \\
\text { AAC }\end{array}$ \\
& ATHB8pr-R & gggTTTGATCCTCTCCGATCTCTC \\
BRII & BRI1cs-F & GAGAAATGAAGACTTTTCAAGCTTCT \\
& & TTCTCTCTG \\
& BRI1cs-R & ctcatgggatccCATAATTTCCTTCAGGAAC \\
& BRI1pr-F & agatcTGCTTGATTATGATGACATTATAG \\
& BRI1pr-R & ggGTTTGTGAGAGAGAAAAGTGGG \\
& BRI1rt-F & CGCATATCATCCACAGAGAC \\
& BRI1rt-R & GTATCCATCGCACTCATCAG \\
TUB2-3 & TUBrt-F & CCAGCTTTGGTGATTTGAAC \\
& TUBrt-R & CAAGCTTTCGGAGGTCAGAG \\
LUC & LUCrt-F & GGAGCACGGAAAGACGATGACGG \\
& LUCrt-F & GGAGCACGGAAAGACGATGACGG \\
\hline
\end{tabular}

Non-complementary nucleotides are shown in lowercase letters
Generation and characterization of transgenic plants

Reporter fusions and chimeric genes were assembled in the pPCV-GUS or pPCV-LUC binary reporter vectors, versions of pPCV812 (Koncz et al. 1994) modified to carry glufosinate resistance and either $\beta$-glucuronidase $(G U S)$ or firefly luciferase $(L U C)$ reporter genes. To generate the BRIIpro:GUS and BRIIpro:LUC reporter constructs, a 1,899-bp segment of the BRII promoter (At4g39400;-1906 to -8 relative to the translational start) was amplified from Col-0 genomic DNA by primers BRI1pr-F and BRI1pr-R (Table 1), which allowed oriented BglII-SmaI insertion in the respective reporter vectors.

For complementation studies, the intronless $3,590 \mathrm{bp}$ BRII coding sequence, without the termination codon, was amplified from genomic DNA using the BRI1cs-F and BRI1cs-R primers (Table 1). To facilitate transgene detection, the $3^{\prime}$ end of the BRII coding sequence was translationally fused to the $L U C$ reporter via the hinge region used by Friedrichsen et al. (2000) in their BRII-GFP fusion. Native $B R I 1$-specific and targeted expression was ensured by fusing the BRII-LUC coding sequence with promoters of BRII, the photosynthetic tissue-specific $C A B 3$ (Mitra et al. 1989), the vasculature-specific SUC2 (Truernit and Sauer 1995), and the procambium-specific ATHB8 (Baima et al. 1995; Kang et al. 2003) genes. The promoters of $C A B 3$ (At1g29910; -988 to -2 ) and SUC2 (At1g22710; -2129 to -2) were available as HindIII-BamHI fragments, the ATHB 8 sequence (At4g32880; -1721 to -2) was PCR isolated using the ATHB8pr-F and ATHB8pr-R primers (Table 1).

Stable transgenic Arabidopsis lines were generated by Agrobacterium-mediated transformation, as described in Bancos et al. (2006). For each fusion construct at least 10 glufosinate-resistant primary transformants were isolated and $\mathrm{T} 2$ progenies were obtained by self-pollination. Homozygous lines were produced from T2 plants that showed 3:1 segregation and, when appropriate, the correct tissue-specificity of the transgene. Representative lines were chosen from those isolates that shared the most frequently observed expression level and pattern for a particular transgene. In the case of the BRII-LUC complementation analyses this selection was based on an initial phenotype comparison of the parallel homozygous lines featuring similar phenotypes (Supplementary Table 1). Subsequent quantitative characterization of inflorescence and silique development was done with 10, two-month-old plants of each representative transgenic line, all grown in parallel, and 50 ripe siliques collected from each batch of these lines.

Detection of reporter gene activity

Histochemical localization of $E$. coli $\beta$-glucuronidase (GUS) reporter activity was carried out according to Jefferson (1987). Seedlings were collected each day after germination (DAG), whereas organ samples were isolated from mature, six-week-old plants. All isolates were immediately fixed by vacuum infiltration with $2 \%$ (w/v) formaldehyde in $50 \mathrm{mM}$ sodium phosphate $(\mathrm{pH} 7.0)$. Following two washes in the same buffer, samples were stained overnight at $37{ }^{\circ} \mathrm{C}$ in a solution containing $0.5 \mathrm{mg} / \mathrm{ml} \mathrm{5-bromo-4-}$ chloro-3-indolyl $\beta$-D-glucuronide (X-Gluc; Biosynth A.G., Staad, Switzerland) in $50 \mathrm{mM}$ sodium phosphate ( $\mathrm{pH}$ 7.0). Stained samples were soaked in multiple changes of $50 \%$ $(\mathrm{v} / \mathrm{v})$ ethanol to remove plant pigments, and then were photographed using Nikon SMZ800 microscope with dark background function.

In vivo luminescence of the firefly luciferase (LUC) reporter was detected at constant $22{ }^{\circ} \mathrm{C}$ temperature as described in Kay et al. (1994), using a liquid nitrogencooled digital CCD camera (LN-CCD-512-TKB, Princeton Instruments, Trenton, NJ, USA). For time-course measurements, patches of 50 one-week-old seedlings on MS medium were sprayed one day before the first exposure with sterile $5 \mathrm{mM}$ Tris-phosphate buffer $(\mathrm{pH}$ 8.0) containing $2.5 \mathrm{mM}$ D-luciferin (Biosynth A.G.) and $0.01 \%(\mathrm{v} / \mathrm{v})$ Triton X-100. For monitoring transgene activity upon germination, seeds were sown over MS medium supplemented with $2.5 \mathrm{mM}$ D-luciferin. Germination in DD was facilitated by a 12 -h illumination period followed by 12 -h dark incubation at $4{ }^{\circ} \mathrm{C}$. Luminescence data were evaluated using Metamorph imaging software (Meta Series 4.5; Universal Imaging). All measurements were repeated at least three times, with four replicates.

\begin{tabular}{lll} 
Journal : Large 425 & Dispatch : 27-1-2014 & Pages : 13 \\
Article No : 2031 & $\square$ LE & $\square$ TYPESET \\
MS Code : PLAA-D-13-00697 & $\square \quad$ CP & $\square \quad$ DISK \\
\hline
\end{tabular}




\section{Transcript analyses}

Samples of total RNA were isolated from batches of 50 one-week-old seedlings using RNeasy Plant Mini Kit (Qiagen). Traces of genomic DNA were removed by treatment with RNase-free DNase (Qiagen). RNA was eluted by RNase-free distilled water and quantitated by $\mathrm{OD}_{260}$ measurements. Samples were adjusted to $1 \mu \mathrm{g} / \mu \mathrm{l}$ concentration and stored at $-20^{\circ} \mathrm{C}$ until use.

For quantitative RT-PCR analyses of relative mRNA levels cDNA was prepared from $1 \mu \mathrm{g}$ total RNA by RevertAid First Strand cDNA Synthesis kit (Fermentas) with random hexanucleotide primers. Measurements, based on SYBR Green fluorescence, were carried out with $1.5 \%$ amounts of the cDNA samples, using 7300 Real Time System and software (Applied Biosystems). Each assay was performed in triplicates, with two biological repetitions. Transcript levels were normalized to those of the constitutively expressed tubulin genes (TUB2, At5g62690 and TUB3, At5g62700). The primers for the BRII (BRI1rt-F and BRI1rt-R), LUC (LUCrt-F and LUCrt-R) and TUB (TUBrt-F and TUBrt-R) reactions are shown in Table 1.

\section{Quantitation of the BRI1-LUC fusion protein}

Batches of 100 DD-grown seedlings, carrying the BRI1pro:BRI1-LUC transgene in bril-101 background, were harvested at 5 DAG. Following removal of the cotyledons and roots the hypocotyls were separated to upper (apical) and lower (basal) halves and were frozen in liquid nitrogen. These samples were then used for analyses of the BRI1-LUC mRNA and BRI1-LUC protein content.

Relative levels of the BRI1-LUC fusion protein were determined by the luminometric method of Viczián and Kircher (2010). In brief, LUC reactions were carried out in microplates using crude extracts prepared from the hyopcotyl samples, and luminescence values were measured using a TopCount NXT luminometer (Perkin-Elmer). Data were normalized to protein content. From the same sets of samples the levels of the BRII-LUC transcript were also determined by RT-PCR using $L U C$-specific primers. The assays were done in triplicate, with two biological replicates.

\section{Results}

BRII expression during germination and early seedling development

To find out how BRII promoter activity is regulated during early Arabidopsis development we visualized GUS reporter activity in BRIIpro:GUS transgenic seedlings by histochemical staining. Under LD conditions (Fig. 1a), GUS staining was not detectable on day 1 following the onset of germination. At days two and three, intense staining appeared in the straightening hypocotyl and in the radicle, primarily around its elongation zone. Later on the GUS activity decreased, but it remained strong near the root tip and well detectable in the petioles. No staining was observed in the cotyledons. Upon DD germination (Fig. 1b), GUS staining was visible from day one in the emerging radicle. During days two and three this became more intense, and strong coloration developed also in the hypocotyl. Subsequently, until day seven, the staining gradually decreased around the joint of the hypocotyl and radicle, and was seen mainly in the distal parts of these organs, near the root tip and, particularly, the hypocotyl hook. DD seedlings, just as those grown in LD, lacked visible GUS staining in their cotyledons.

Enhanced BRII expression is accompanied by accumulation of the $\mathrm{BR}$ receptor

In the hypocotyl of DD seedlings GUS activity decreased in the basal region, but increased in the apical part after day four (Fig. 1b). To examine whether the observed unequal activity of the BRII promoter influences local accumulation of the BRII transcript and the encoded receptor, we determined the relative levels of the respective mRNA and protein in the basal and apical halves of five-day-old DD seedlings.

To facilitate detection of the BR receptor, we used a line carrying the BRIIpro:BRII-LUC transgene in bril-101 background. In this line, BR insensitivity is fully complemented by the BRII coding sequence fused in frame to the $5^{\prime}$ end of the $L U C$ reporter, and the plants are morphologically indistinguishable from those of the Col-0 wild type (Supplementary Fig. S1a). Our quantitative RT-PCR analyses revealed that in the apical segment of the hypocotyls the abundance of BRI1:LUC mRNA was nearly fivefold higher than the level detected in the basal part (Fig. 2a). Luminescence-based assays showed similar accumulation of the BRI1:LUC protein in the apical region of the hypocotyls, which contained about 12.5-fold larger amount of the receptor-reporter fusion than the basal segment (Fig. 2b). These data indicate good correlation between BRII gene expression and the accumulation of the BRI1 receptor.

Time course of BRII induction in young seedlings

To determine the temporal profile of the observed BRII induction during early Arabidopsis development we followed the in vivo luminescence of BRIIpro:LUC seedlings throughout the first week following germination (Fig. 3). In these experiments both LD and DD seedlings

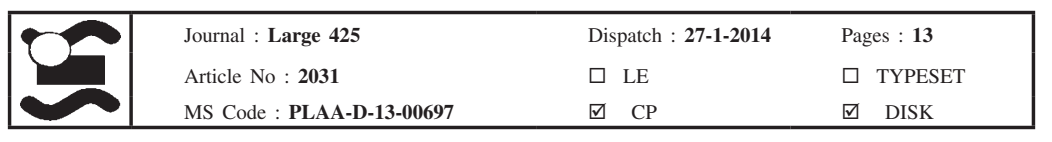



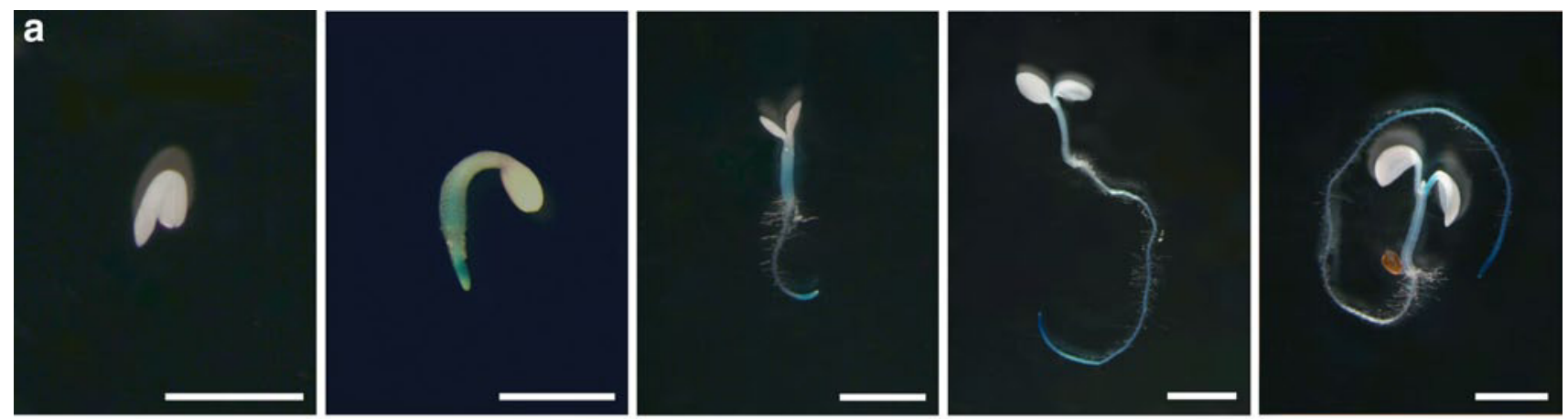

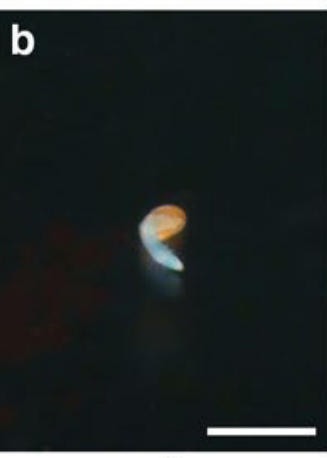

1

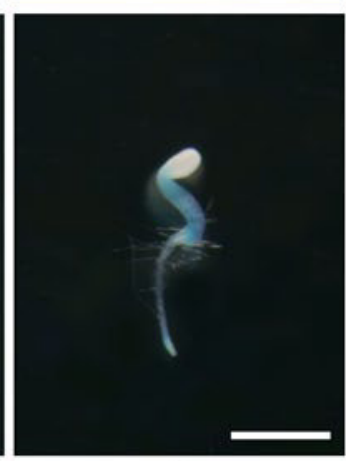

2

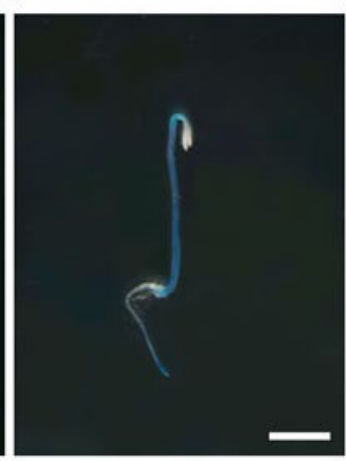

3

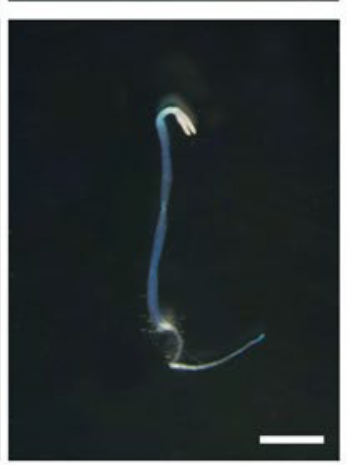

4

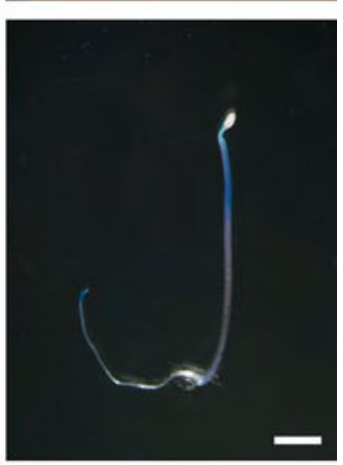

7 DAG

Fig. 1 Histochemical staining of GUS activity in BRI1prom:GUS transgenic seedlings during the first seven days after germination (DAG). a Seedlings germinated and grown in LD cycles. b Seedlings germinated and grown in DD. Scale bars correspond to $2 \mathrm{~mm}$

showed strong increase of LUC activity between days one and three. In LD samples the expression reached its maximum on day three, and then decreased to roughly half of that level by day four, after which it continued in a periodic pattern with maxima at the dark periods (Fig. 3a). In the first three days after germination DD induction of the BRII promoter activity was very similar to that observed in LD. Later on, however, the luminescence intensity of DD seedlings remained at an almost stable high level, well above the corresponding LD values, until day 6 (Fig. 3b).

\section{BRII expression in mature plants}

Our results show organ-specific regulation of BRII transcription in young seedlings, indicating that differential expression may be maintained throughout the later stages of development. Therefore, we examined the pattern of $B R I 1$ promoter activity in rosettes and reproductive organs of BRII-GUS transgenic plants by GUS histochemical analysis.

In pre-bolting rosettes of five-week-old plants GUS staining was observed in young, expanding leaves, mainly in the petioles and proximal parts of the central veins. Only very weak or no activity could be detected in older leaves and in the roots (Fig. 4a). Also low level expression was seen in the flowers, where staining occurred only at the joining of the pedicel and over the stigma (Fig. 4b). By contrast, much stronger GUS activity could be detected in immature siliques, in which staining was most intense in the developing seeds (Fig. 4c, d).

Diurnal and light regulation of $B R I I$ promoter activity

In young LD-grown seedlings we found that following a strong, transient induction BRII promoter activity adopted a pattern of daily fluctuation, which became regular by the end of the first week after germination (Fig. 3a). To characterize this periodic regulation we determined the changes of luminescence intensity in seven-day-old LDgrown BRIIpro:LUC seedlings. In these in vivo timecourse measurements we observed daily cycles of weaker transgene activity during the illumination periods and stronger expression in the dark phases (Fig. 5a). Relative to the beginning and end of the photoperiods, a moderate increase of the expression levels could be seen around the middle of both the light and dark stages.

Under LD conditions the abrupt changes of luminescence intensity were detected following lights on and lights off, suggesting that BRII transcriptional activity is influenced by light conditions. Therefore, we also measured the luminescence profiles of seven-day-old BRIIpro:LUC seedlings upon transfer from LD to LL or DD. In these

\begin{tabular}{|l|ll|}
\hline Journal : Large 425 & Dispatch : 27-1-2014 & Pages : 13 \\
Article No : 2031 & $\square$ LE & $\square$ TYPESET \\
MS Code : PLAA-D-13-00697 & $\square \quad C P$ & $\square$ DISK \\
\hline
\end{tabular}



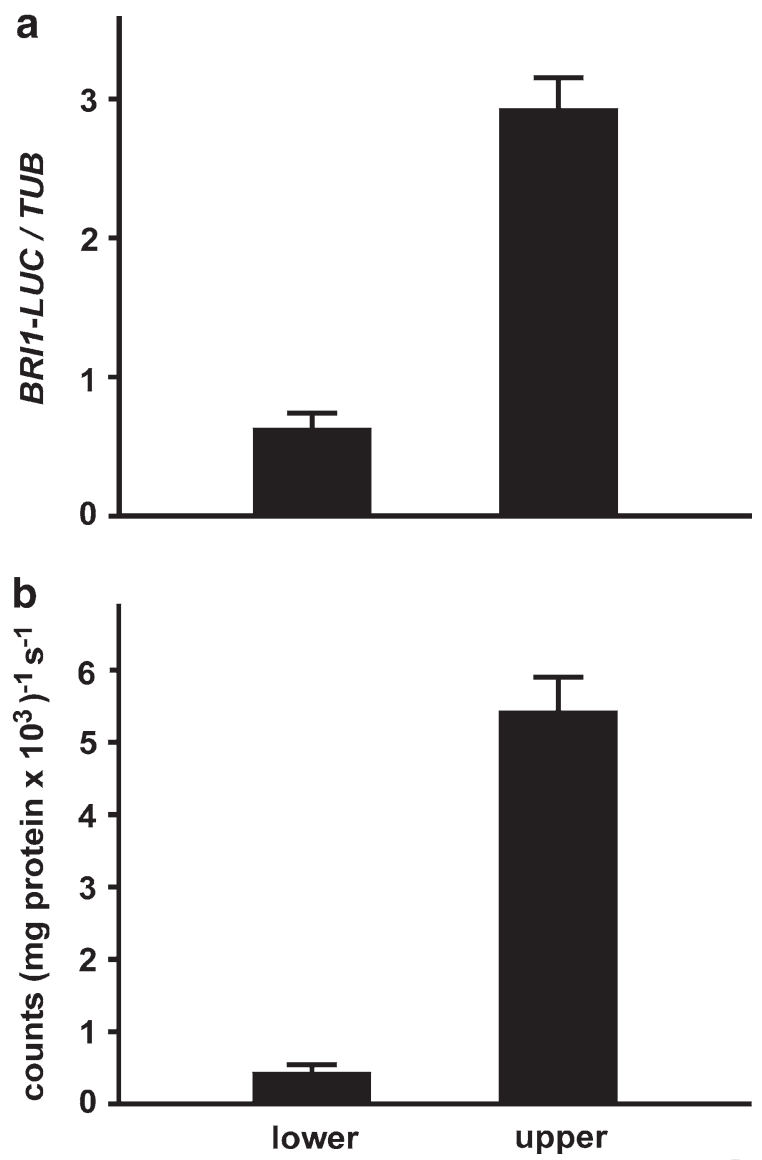

Fig. 2 Differential accumulation of the BRII-LUC transcript and BRI1-LUC fusion protein in the hypocotyls of DD-grown BRIlpro m:BRI1:LUC/bri1-101 seedlings. a Relative levels of the BRI1-LUC mRNA in the lower and upper halves of 5 DAG seedlings. Quantitative RT-PCR measurements were carried out using $L U C$-specific primers. b Luminescence generated by the BRI1-LUC fusion protein in the lower and upper halves of 5 DAG seedlings. The data represent mean values $\pm \mathrm{SD}$ experiments we found that from the onset of LL the pattern of expression changed to a low-amplitude oscillation with roughly $24-\mathrm{h}$ periodicity, showing maxima toward the end of the subjective light periods (Fig. 5b). This circadian type regulation of BRII activity was maintained for at least 3 days in LL. By contrast, the shift to DD resulted in a more or less steady expression, close to the maximum level of the last LD cycle, with only barely recognizable circadian changes (Fig. 5c).

To further elucidate the regulatory role of light, we also measured the time course of BRII expression using LD conditioned seven-day-old seedlings that were moved to DD for $60 \mathrm{~h}$, and then returned to LD cycles (Fig. 6a). Compared to the LD control (Fig. 6b), the intensity of luminescence remained relatively high and constant during the DD phase, just as it has been in extended DD (Fig. 5c). Then, upon return to LD, the first 'lights on' decreased the
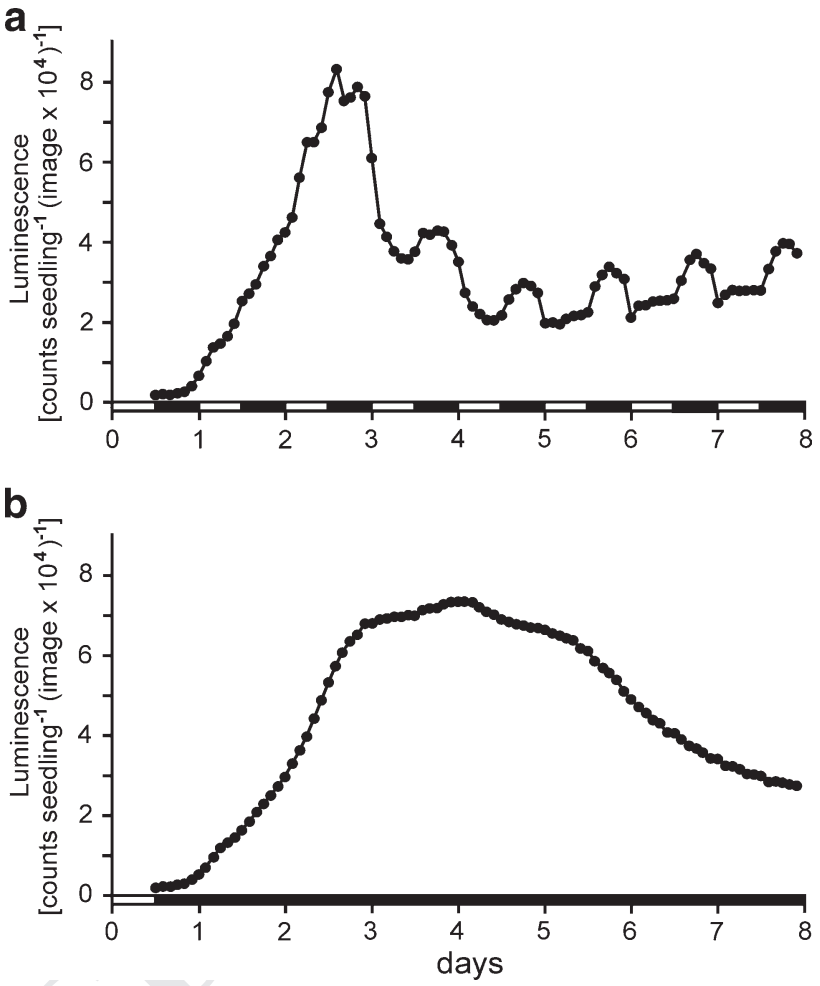

Fig. 3 Luminescence intensities of BRI1prom:LUC seedlings during germination and early seedling development. a LD germinated and raised seedlings. b DD germinated and raised seedlings. Zero time is the start of germination following the cold treatment at $4{ }^{\circ} \mathrm{C}$. In the time scale white and black bars indicate light and dark phases. Each panel shows the result of a representative measurement

level of expression to approximately half of the preceding dark values within $4 \mathrm{~h}$. Following this sharp decline the luminescence profile resumed the biphasic periodicity which is characteristic for the LD seedlings (Fig. 6a, b).

Developmental consequences of ectopic BRII expression

Our results revealed complex regulation of BRII gene activity, suggesting that these expressional control mechanisms can influence plant development by modulating the availability of the BR receptor. Therefore, we assumed that altering the expression pattern would have well-recognizable developmental consequences. We tested this possibility in transgenic Arabidopsis lines expressing BRII under the control of well-characterized tissue-specific promoters.

We analysed the developmental effects of targeted BRII misexpression by complementing the bri1-101 mutant with the BRII-LUC gene fusion driven by the photosynthesis-associated $C A B 3$, the vascular tissue-specific $S U C 2$, or the procambium-specific $A T H B 8$ promoters. When comparing the transcript level of seven-day-old seedlings to that of BRIIpro:BRII-LUC/bril, it was roughly double in CAB3pro:BRI1-LUC/bril, approximately the

\begin{tabular}{|llll|} 
Journal : Large 425 & Dispatch : 27-1-2014 & Pages : 13 \\
Article No : 2031 & $\square$ LE & $\square$ TYPESET \\
MS Code : PLAA-D-13-00697 & $\square \quad$ CP & $\square \quad$ DISK \\
\hline
\end{tabular}


Fig. 4 GUS activity in mature BRIlprom: GUS plants. a Fiveweek-old rosette. b A flower. c, d Segments of opened immature siliques
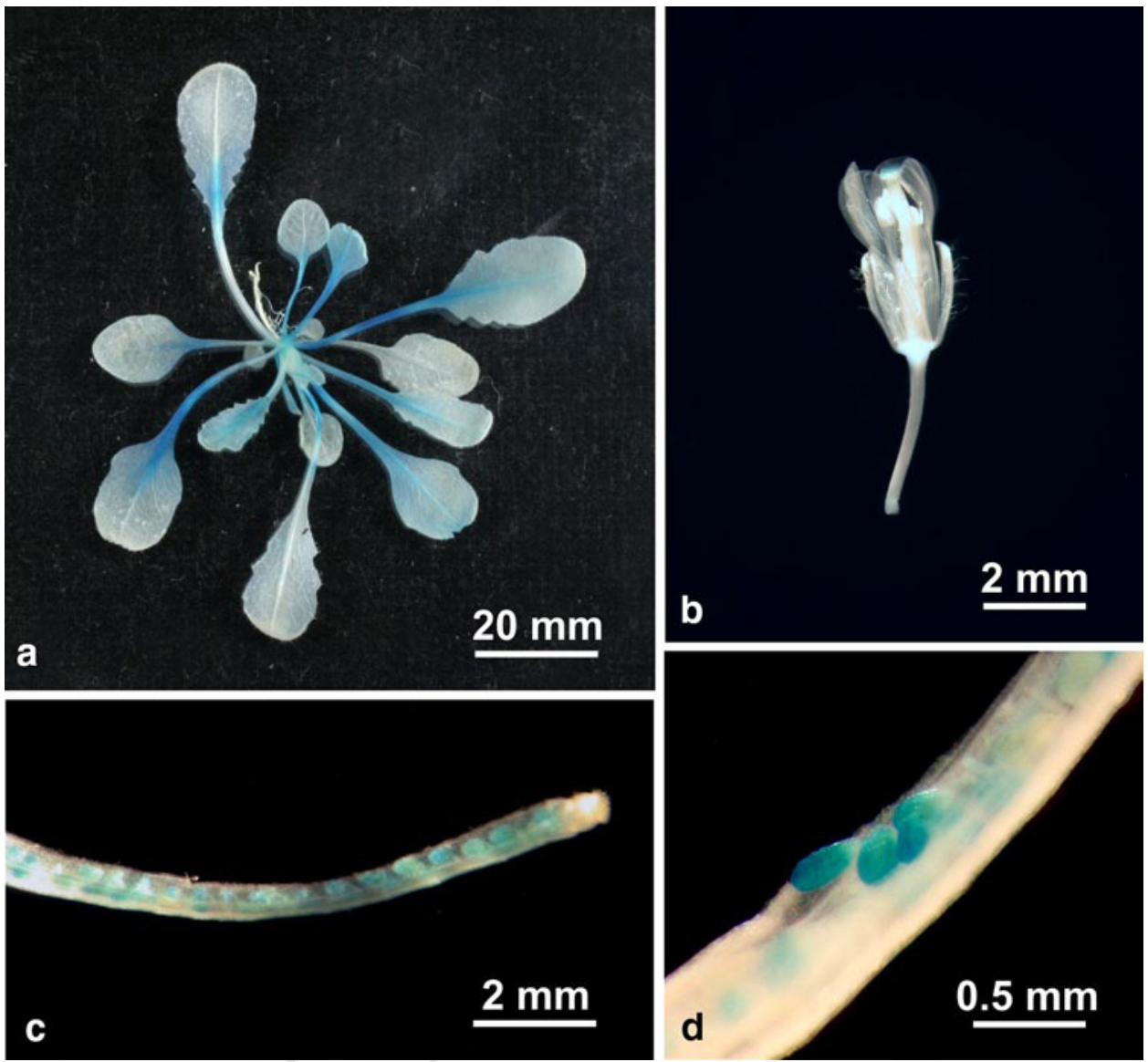

same in SUC2pro:BRII-LUC/bril, and less than $15 \%$ in ATHB8pro:BRI1-LUC/bril plants (Fig. 7a). The leaves of five-week-old CAB3pro:BRI1-LUC/bril rosettes had hyponastic blades and longer petioles than those of the BRII pro:BRII-LUC/bril control. The expression of the transgene, as revealed by LUC activity, was observed over the entire area of the leaves, but was not visible in the root system (Fig. 7b, c). SUC2pro:BRI1-LUC/bril plants of the same age had severe dwarf phenotype, similar to that of the non-complemented bri1-101 mutant. Their luminescence was much weaker in the mature leaves, and only moderately stronger in the expanding leaves and the root (Fig. 7d). The ATHB8pro:BRI1-LUC/bril transgenic lines had semidwarf rosettes with flat, rounded leaves. In these plants most of the luminescence was observed in the veins of the leaves and in the roots (Fig. 7e).

The developmental consequences of ectopic BRII expression were clearly visible in two-month-old mature plants. When compared to Col-0, the CAB3pro:BRIILUC/bril line showed close resemblance, with an inflorescence of comparable height, leaves of similar size, and only slightly shorter siliques with nearly the same number of seeds (Fig. 8a, b; Table 2). By contrast, size proportions between the organs of SUC2pro:BRI1-LUC/bril were severely distorted. While the leaves were short and epinastic as those of the bri1-101, the inflorescence stem became much more elongated, reaching more than half the height of Col-0 (Fig. 8a, b; Table 2). The siliques were only about half as long as those of the wild type and contained much fewer seeds (Table 2). The ATHB8pro:BRI1-LUC/bril plants were more or less proportionately dwarfed, featuring rounded but flat leaves and inflorescence stems approximately twice higher than those of bril-101 (Fig. 8a, b; Table 2). The average length of the siliques was only about two-thirds compared to that of Col- 0 , but they produced nearly the same number of seeds (Table 2).

\section{Discussion}

An earlier analysis of BRI1 expression and localization, which used a BRIIprom:BRII-GFP transgenic line, indicated that in Arabidopsis seedlings the distribution of the receptor is not spatially regulated (Friedrichsen et al. 2000). This result was in line with RNA gel blot and mRNA microarray hybridisation data ( $\mathrm{Li}$ and Chory 1997; Goda et al. 2002), which showed only moderate variation of BRII transcript levels between mature organs. These studies

\begin{tabular}{|llll|} 
Journal : Large 425 & Dispatch : 27-1-2014 & Pages : 13 \\
Article No : 2031 & $\square \quad$ LE & $\square$ TYPESET \\
MS Code : PLAA-D-13-00697 & $\square \quad C P$ & $\square$ DISK \\
\hline
\end{tabular}



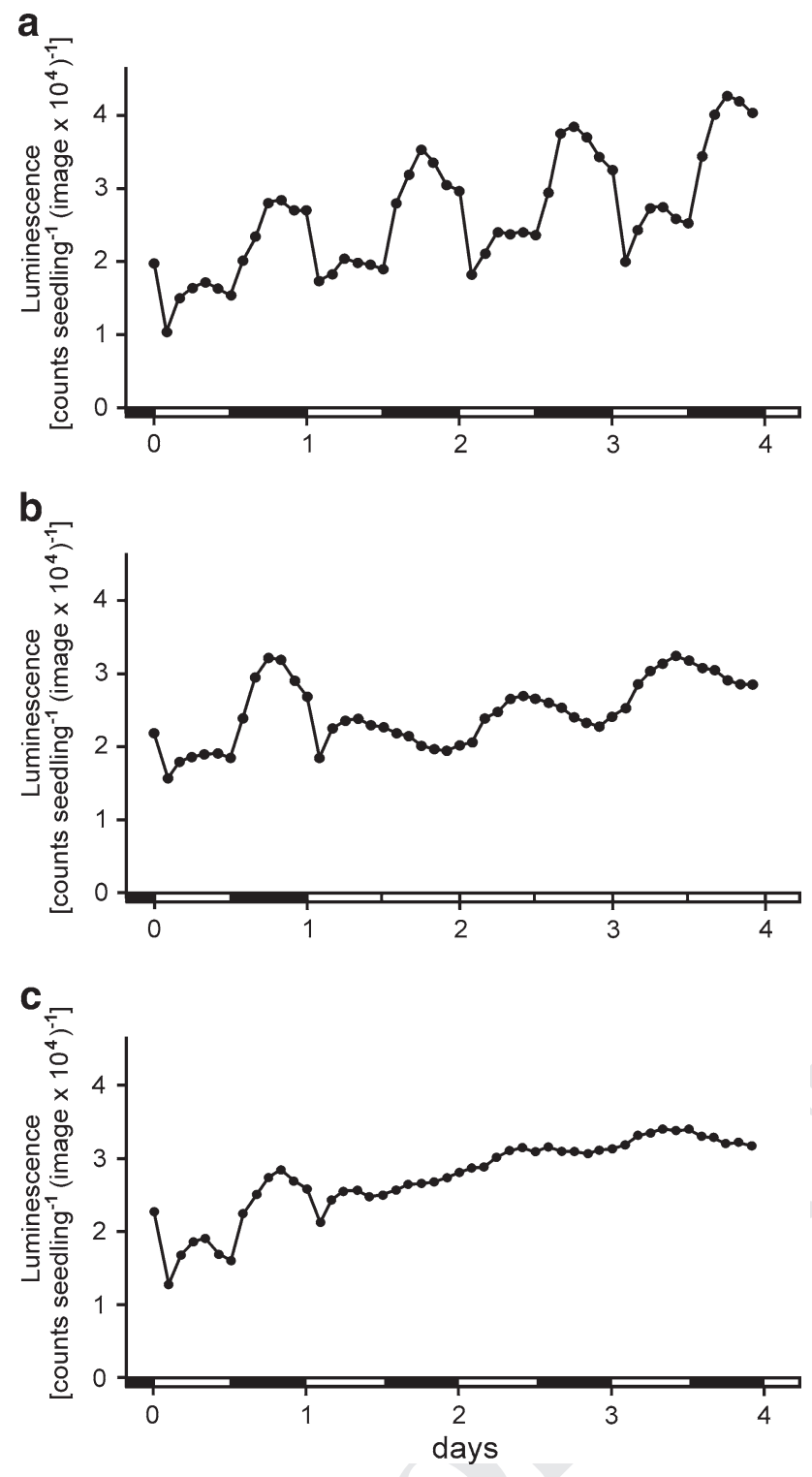

Fig. 5 Luminescence profiles of one-week-old LD conditioned BRIIprom:LUC seedlings. a In LD. b Upon shift from LD to LL. c Upon shift from LD to DD. Zero time is the onset of the last common light period. In the time scale white and black bars indicate light and dark phases, whereas grey bars correspond to subjective dark (b) or subjective light (c) periods. Each panel shows the result of a representative measurement

implied that BRI1 abundance may not have an important role in influencing differential BR responses, which could depend primarily on local levels of the active hormone.

Other results, however, suggested that physiological responses to BRs are also influenced by differential hormone susceptibility. Müssig et al. (2003) reported that while 24-epiBL stimulated root growth at sub-nanomolar concentrations, the nanomolar concentrations that promoted hypocotyl elongation were already inhibitory to root development. Dark-grown seedlings were found to be more
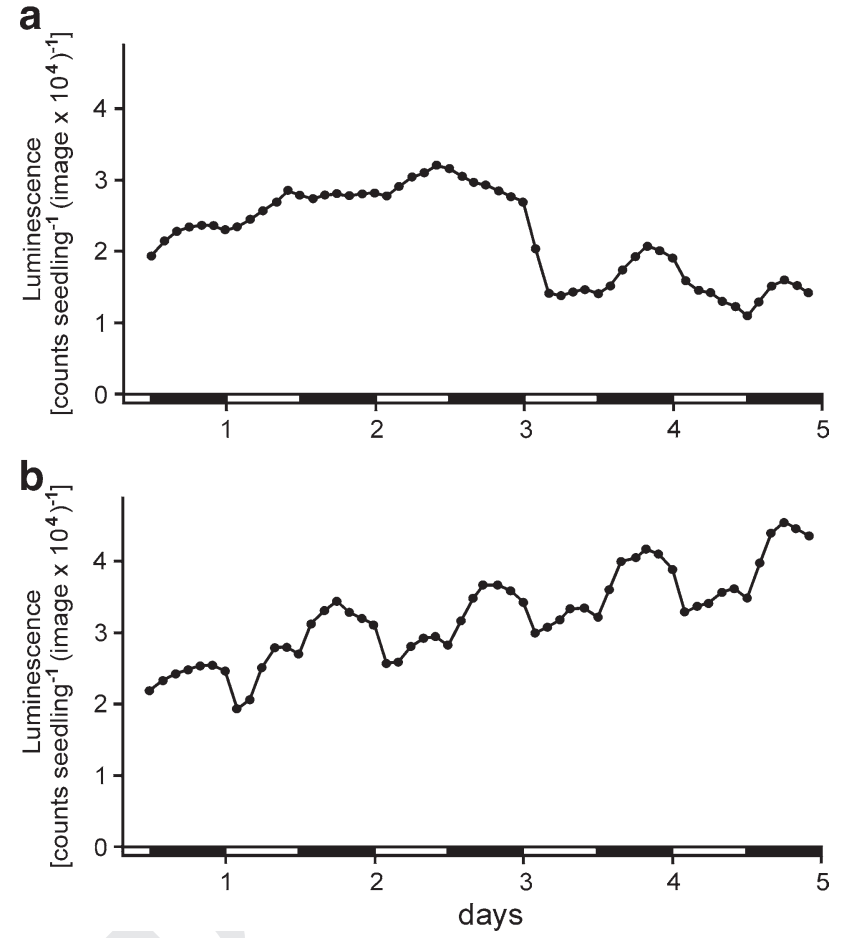

Fig. 6 Luminescence responses of one-week-old LD conditioned BRI1prom:LUC seedlings to changing light regimes. a Shift from LD to DD from lights off on day 1 , and then back to LD from lights on of day 3. b LD control. Zero time is the onset of the last common light period. White and black bars indicate light and dark phases; grey bars correspond to subjective light periods. Each panel shows the result of

a representative measurement

responsive to treatments with exogenous $\mathrm{BL}$ or 24-epiBL than those raised under light-dark conditions (Turk et al. 2003; Yang et al. 2005). It was also observed that in seedlings exposed to prolonged darkness the BR-repressible $C P D$ gene became strongly downregulated, despite the unchanged level of active BRs (Bancos et al. 2006). These results seemed to indicate that the regulation of BR sensitivity could have a role in enhancing or attenuating physiological responses to the hormone.

Whereas the extent of BR effects can be influenced by the availability and/or phosphorylation state of downstream signalling components (Kim and Wang 2010), the abundance of the BRI1 receptor, which directly interacts with the hormone and initiates the signalling process, is crucial in regulating the responses. Accordingly, a receptor-overexpressing line shows phenotypic features consistent with enhanced BR exposure (Wang et al. 2001), similar to those seen in plants that overproduce the hormone (Choe et al. 2001). As de novo synthesis is assumed to be an important factor in determining the availability of the receptor, we wanted to find out how the expression of BRII is regulated in Arabidopsis. To this end we generated transgenic plants

\begin{tabular}{|l|lll|}
\hline Journal : Large 425 & Dispatch : 27-1-2014 & Pages : 13 \\
Article No : 2031 & $\square$ LE & $\square$ TYPESET \\
MS Code : PLAA-D-13-00697 & $\square \quad C P$ & $\square \quad$ DISK \\
\hline
\end{tabular}


Fig. 7 Ectopic expression of BRI1-LUC in bri1-101 mutant background. a Relative levels of the BRI1-LUC transcript expressed under the control of the BRII, CAB3, SUC2 and ATHB8 promoters in one-week-old transgenic seedlings with bril-101 background. Quantitative RT-PCR measurements were carried out using $L U C$-specific primers. The data represent mean values $\pm \mathrm{SD}$. b-e Morphology (left) and luminescence (right) images of onemonth-old BRI1prom:BRI1-LUC (b), CAB3prom:BRI1-LUC (c), SUC2prom:BRII-LUC (d) and ATHB8prom:BRII-LUC (e) transgenic rosettes. Scale bars correspond to $1 \mathrm{~cm}$

that express the readily detectable GUS or LUC reporters under the control of the BRII promoter.

Our histochemical analyses of BRIIpro:GUS seedlings revealed characteristic developmental and organ-specific patterns of BRII promoter activity. Following germination GUS staining was seen primarily in the hypocotyls and the distal part of the radicle, but could not be observed in the cotyledons. Although GUS activity appeared earlier and became more intense in DD- than in LD-grown seedlings, its localization was similar under both types of light regimes (Fig. 1). Following day fourth the staining of DD hypocotyls became stronger toward the cotyledons (Fig. 1b).

To test whether our GUS histochemical assays reliably reflected differences in BRII expression, we determined the relative levels of mRNA and receptor accumulation in the upper and lower halves of DD hypocotyls isolated from 5 DAG BRIIpro:BRI1-LUC/bril-101 seedlings. In this transgenic line BRI1 was replaced by the easily detectable BRI1-LUC chimeric receptor that could fully restore wild-type BR sensitivity in the mutant background (Supplementary Fig. S1). The quantitative analyses also showed elevated amounts of the BRII-LUC transcript and the receptor-reporter fusion protein in the upper hypocotyl region (Fig. 2a, b). At this stage of DD development the elongation of epidermal cells is restricted to the apical region of the hypocotyl (Gendreau et al. 1997), and MDP40, a BR-controlled regulator of the elongation process, is preferentially expressed in the upper half of the hypocotyl (Wang et al. 2012b). Correlation between BRII transcriptional activity and the receptor level could also be observed when comparing two-week-old BRIlprom:LUCl Col-0 and BRIIprom:BRII-LUC/bril-101 plantlets, which both showed luminescence primarily in the expanding leaves and near the root tips (Supplementary Fig. S1b, c). Whereas the receptor activities of BRI1 and its LUCtagged version may slightly differ, these data suggest that the upregulation of BRII gene activity contributes to the accumulation of the receptor and, at least during DD elongation of the hypocotyl, also to the enhancement of BR signalling.
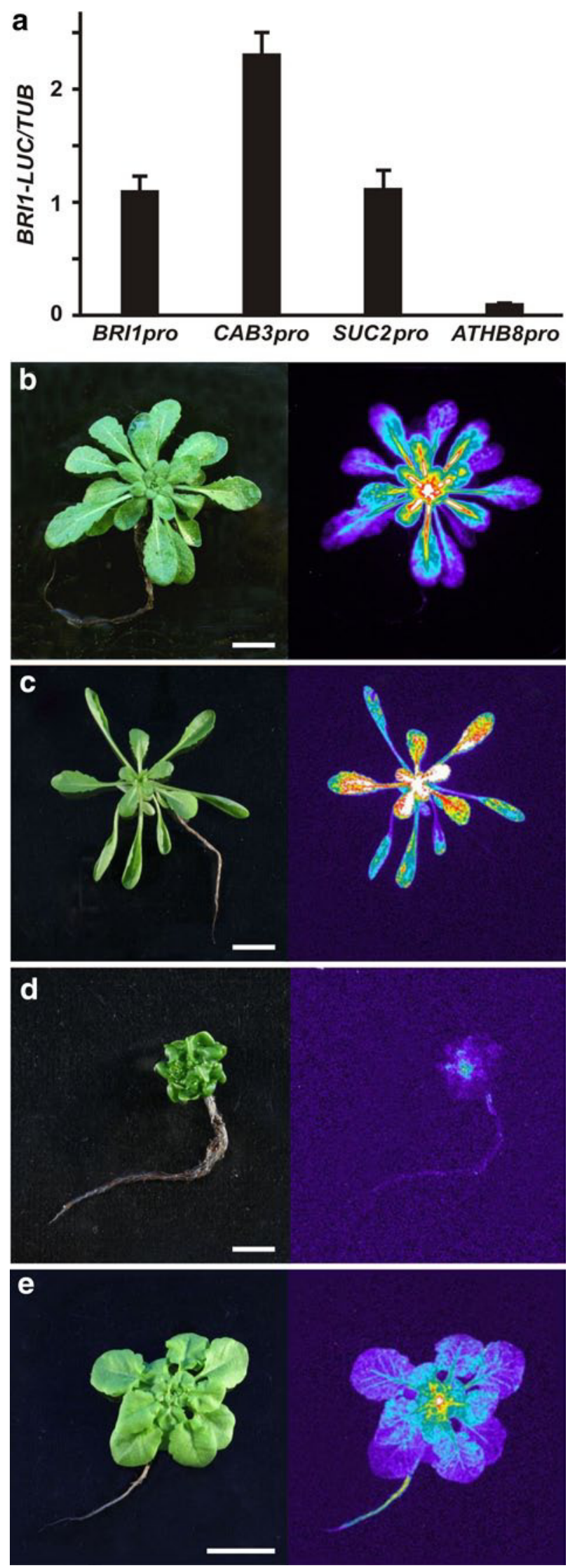

\begin{tabular}{|llll|} 
Journal : Large 425 & Dispatch : 27-1-2014 & Pages : 13 \\
Article No : 2031 & $\square \quad$ LE & $\square$ TYPESET \\
MS Code : PLAA-D-13-00697 & $\square \quad C P$ & $\square$ DISK \\
\hline
\end{tabular}



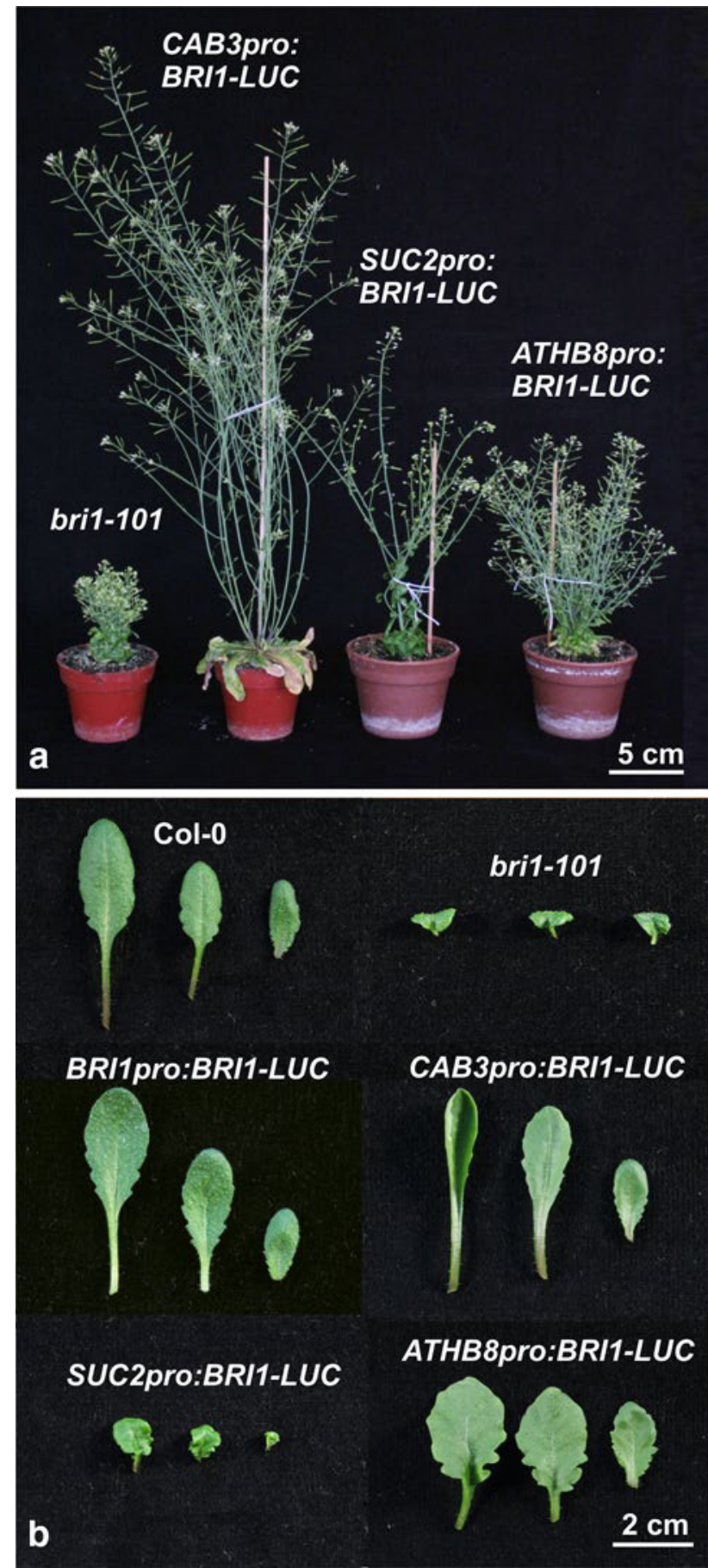

Fig. 8 Morphology of transgenic plants with ectopic expression of BRI1. a Mature, two-month-old plants. b Leaves isolated from sixweek-old rosettes

BRIIpro:GUS plants provided information on the the reporter (Millar et al. 1992) permits quasi real-time expression analyses. Our data showed a strong induction of BRII during the first three days following germination, and that this was largely independent of the light conditions (Fig. 3a, b). Subsequently, BRII activity was quickly repressed in $\mathrm{LD}$, falling back to about half of the day three maximum value within $24 \mathrm{~h}$ (Fig. 3a). By contrast, the level of expression in DD remained high for further 2 to 3 days, and then decreased gradually (Fig. 3b), reaching a value similar to the LD control only by day seven.

The expression analyses using promoter-reporter fusion transgenic lines revealed apparent coincidence between BRdependent morphogenic events and the levels of BRII gene activity. In seedlings, the intense GUS staining of LL root tips and DD hypocotyls was in good agreement with preferential elongation of these regions under the mentioned light regimes. Earlier studies found similar expression patterns of Arabidopsis CYP85A2 and tomato (Solanum lycopersicum) CYP85A1 (Castle et al. 2005; Montoya et al. 2005), the genes encoding the main C-6 oxidase enzymes required for the synthesis of bioactive BRs in these species (Bishop et al. 1999; Shimada et al. 2003). Furthermore, the strong BRII activity of developing Arabidopsis seeds (Fig. 4c, d) is accompanied by enhanced CYP85A2 expression (Castle et al. 2005), and concomitant induction of the genes that encode the BRI1 and CYP85 orthologues has also been observed in germinating pea (Pisum sativum) (Nomura et al. 2007). BRs have an important role in seed and fruit development (Huang et al. 2013), and combined mRNA and BR analyses in various dicot species revealed that induction of the CYP85 genes during these processes results in transient accumulation of bioactive BRs (Montoya et al. 2005; Nomura et al. 2005, 2007; Symons et al. 2006). Taken together, these results support the notion that local induction of BR biosynthesis, and the resulting accumulation of the hormone, tends to coincide with enhanced BRII expression.

In LD-grown seedlings BRII promoter activity exhibits a recognizable diurnal periodicity, with expression levels higher in the dark and lower during the light periods (Fig. 5a). The observed biphasic pattern results from a weak circadian fluctuation showing maxima at the middle of the subjective light periods, and a superimposed negative light regulation that allows strongest activity during the dark phases (Fig. 5a-c). The circadian minima and maxima are clearly recognizable on the diurnal pattern, which, however, is determined primarily by the light regulation. Whereas the circadian oscillation is well recognizable in LL, its amplitude is strongly dampened in DD. This is probably due to the elevated, near-maximum expression of BRIl in the dark (Fig. 5c). The functional significance of the diurnal regulation of BRII is not clear, but it seems likely that it can cause periodic daily changes in receptor availability and, hence, BR responsiveness.

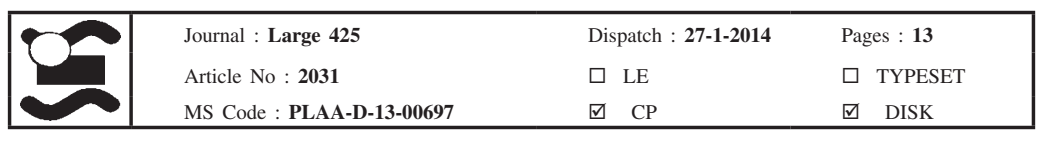


Table 2 Inflorescence and silique development in BRII$L U C$-complemented lines

Data are mean values \pm SD

\begin{tabular}{lccc}
\hline Arabidopsis line & Inflorescence height $(\mathrm{mm})$ & Silique length $(\mathrm{mm})$ & Seeds per silique \\
\hline Col-0 & $396 \pm 52$ & $13.6 \pm 0.9$ & $40 \pm 5$ \\
bri1-101 & $63 \pm 9$ & $6.5 \pm 0.6$ & $8 \pm 3$ \\
BRI1pro:BRI1-LUC & $388 \pm 68$ & $14.4 \pm 0.8$ & $41 \pm 7$ \\
CAB3pro:BRI1-LUC & $412 \pm 75$ & $12.9 \pm 1.0$ & $37 \pm 7$ \\
SUC2pro:BRI1-LUC & $227 \pm 40$ & $6.7 \pm 0.8$ & $27 \pm 4$ \\
ATHB8pro:BRI1-LUC & $149 \pm 14$ & $10.9 \pm 0.8$ & $38 \pm 3$ \\
\hline
\end{tabular}

Earlier studies revealed that in Arabidopsis seedlings BR responses depend on light conditions and the time of the day. Yang et al. (2005) observed that $1 \mu \mathrm{M}$ 24-epibrassinolide promoted hypocotyl elongation in LD seedlings, whereas in the DD control the concentrations above $10 \mathrm{nM}$ were already inhibitory. Upon prolonged DD exposure of LD-grown seedlings the BR-repressible $C P D$ expression decreased dramatically, though the level of active endogenous BRs remained unchanged (Bancos et al. 2006). It has also been described that under short-day conditions shifting the peak of BRII transcript accumulation from the end to the beginning of the dark period can alter the rescue effect in the strong bril-116 mutant background (Michael et al. 2008). Considering that the half-life of the BRI1 protein is approximately $5 \mathrm{~h}$ (Geldner et al. 2007), these results suggest that light regulation of BRII transcription can be a means of modulating receptor abundance and BR susceptibility.

The complex regulation of BRII expression implies that differential expression is important for ensuring the proper BR control of developmental processes. Therefore, to verify that inappropriate regulation of $B R I I$ gene activity interferes with normal morphogenesis, we generated transgenic lines expressing the receptor ectopically. We used BRII$L U C$ fusion, which allowed easy localization of the receptor. The fusion protein contained the same linker peptide as that of the chimeric BRI1-GFP (Friedrichsen et al. 2000), in which the receptor function was not compromised. As expected, the BRIIpro:BRI1-LUC fusion restored the wild phenotype in the strong BR insensitive bril-101 mutant (Supplementary Fig. S1a).

When compared to wild-type Col-0 and the BRIIpro:BRII-LUC-complemented line, we found very similar phenotype in the CAB3pro:BRII-LUC line. Although these plants had more elongate, hyponastic leaves, their inflorescence height, silique length and seed number were very close to those of the wild type (Fig. 8a, b; Table 2). This is consistent with the strong, photosynthetic tissue-specific activity of the $C A B 3$ promoter, and the observation that the rosette versus root distribution of the BRI1-LUC fusion product is comparable in the CAB3pro:BRI1-LUC and BRIIpro:BRII-LUC plants (Fig. $7 \mathrm{~b}, \mathrm{c}$ ). The longer, hyponastic leaves of the
CAB3pro:BRI1-LUC line can be attributed to an enhanced receptor production in the mesophyll cells, which seems to result in a stronger BR-dependent elongation and expansion at the abaxial side of the leaf blade. In contrast to the CAB3pro:BRII-LUC plants, only partial and disproportional complementation could be seen in the transgenic lines that expressed BRI1 under the control of vascular tissue-specific promoters. Whereas SUC2pro:BRII-LUC plants developed about threefold higher inflorescence than bri1-101, the shape and size of its rosette leaves and the length of its siliques did not appreciably differ from those of the non-complemented mutant. Despite their similar appearance, the seed production of the SUC2pro:BRIILUC siliques was substantially higher than those of the mutant (Fig. 8a, b; Table 2). The ATHB8pro:BRII-LUC line also showed reduced inflorescence height and leaf expansion, but in this case the complementation was stronger in the rosette leaves and weaker in the inflorescence stems. Despite the shorter siliques, their seed number was roughly equal to those of the wild type (Fig. 8a, b; Table 2). These results, in agreement with the findings of Savaldi-Goldstein et al. (2007), show that primarily vascular expression of BRII can only partially restore BR sensitivity in severe bril mutants. The observed phenotypic differences between the SUC2pro:BRI1-LUC and ATHB8pro:BRII-LUC plants likely result from the differing activity and developmental regulation of the phloem-specific SUC2 (Truernit and Sauer 1995) and the strictly procambium-specific ATHB 8 (Kang et al. 2003) promoters. Our results show that ectopic expression of BRII can severely disturb the development of Arabidopsis plants, and that correct spatial and temporal transcriptional control of the receptor gene is required for the proper coordination of organ morphogenesis.

In addition to BR levels, the initiation of signalling by this hormone also depends on the availability of BRI1 and its SERK-type co-receptor. A transgenic line overexpressing the BRI1-GFP fusion showed excess leaf elongation, similar to that observed in BR overproducing plants, and the BR-binding capacity of its microsome fractions was found higher than that of the wild type (Wang et al. 2001). Similar, but less pronounced enhancement of BR effects could be observed when the co-receptor BAK1/SERK3 was overexpressed (Nam and Li 2002). This weaker effect

\begin{tabular}{|l|ll|} 
Journal : Large 425 & Dispatch : 27-1-2014 & Pages : 13 \\
Article No : 2031 & $\square$ LE & $\square$ TYPESET \\
MS Code : PLAA-D-13-00697 & $\square \quad C P$ & $\square$ DISK \\
\hline
\end{tabular}


and the semidwarf phenotype of the bak1-1 null mutant ( $\mathrm{Li}$ et al. 2002) can be attributed to the functional redundancy between BAK1/SERK3 and three other members of the SERK family (Gou et al. 2012) which, in addition to their role in the BR receptor complexes, also function as co-receptors in pathogen-induced defence signalling pathways (Roux et al. 2011). Although SERK co-receptors are indispensable for the initiation of BR signalling (Gou et al. 2012), the formation of active receptor complexes seems to be limited by the less abundant BRI1 component. Our results indicate that in Arabidopsis BRII gene activity is under complex regulation, and that this transcriptional control has a role in determining the distribution of the receptor. The data of the complementation analyses support the notion that in BR insensitive background proper restoration of the wild phenotype requires BRII promoter-specific differential regulation of the receptor gene.

We demonstrated that BRII expression is under developmental, organ-specific and diurnal regulation. In addition, it is also controlled by phytohormones, as BRs can downregulate (Goda et al. 2002), whereas auxin can enhance the level of transcription (Nemhauser et al. 2004; Sakamoto et al. 2013). Thus, the activity of BRII is determined in a complex way, similar to that of the key $B R$ biosynthetic genes (Hategan et al. 2011; Zhao and Li 2012). This can allow optimal coordination of BR accumulation and susceptibility, and suggests that the differential regulation of receptor abundance is an important means of enhancing or attenuating physiological effects of the hormone.

Acknowledgments This work was supported by the Hungarian Scientific Research Fund (Grant T 68201) and the 'BRAVISSIMO' Marie Curie Initial Training Grant of the European Union. The authors thank Márta Börcsök S. and Mária Tóth S. for their help with preparing the photographic material.

\section{References}

Baima S, Nobili F, Sessa G, Lucchetti S, Ruberti I, Morelli G (1995) The expression of the Athb- 8 homeobox gene is restricted to provascular cells in Arabidopsis thaliana. Development 121:4171-4182

Bancos S, Nomura T, Sato T, Molnár G, Bishop GJ, Koncz C, Yokota T, Nagy F, Szekeres M (2002) Regulation of transcript levels of the Arabidopsis cytochrome P450 genes involved in brassinosteroid biosynthesis. Plant Physiol 130:504-513

Bancos S, Szatmári A-M, Castle J, Kozma-Bognár L, Shibata K, Yokota T, Bishop GJ, Nagy F, Szekeres M (2006) Diurnal regulation of the brassinosteroid-biosynthetic $C P D$ gene in Arabidopsis. Plant Physiol 141:299-309

Bishop GJ, Harrison K, Jones JDG (1996) The tomato Dwarf gene isolated by heterologous transposon tagging encodes the first member of a new cytochrome P450 family. Plant Cell 8:959-969

Bishop GJ, Nomura T, Yokota T, Harrison K, Noguchi T, Fujioka S, Takatsuto S, Jones JDG, Kamiya Y (1999) The tomato DWARF enzyme catalyses C-6 oxidation in brassinosteroid biosynthesis. Proc Natl Acad Sci USA 96:1761-1766

Caño-Delgado A, Yin Y, Yu C, Vafeados D, Mora-Garcia S, Cheng JC, Nam KH, Li J, Chory J (2004) BRL1 and BRL3 are novel brassinosteroid receptors that function in vascular differentiation in Arabidopsis. Development 131:5341-5351

Castle J, Szekeres M, Jenkins G, Bishop GJ (2005) Unique and overlapping expression patterns of Arabidopsis CYP85 genes involved in brassinosteroid C-6 oxidation. Plant Mol Biol 57:129-140

Choe S, Fujioka S, Noguchi T, Takatsuto S, Yoshida S, Feldmann K (2001) Overexpression of DWARF4 in the brassinosteroid biosynthetic pathway results in increased vegetative growth and seed yield in Arabidopsis. Plant J 26:573-582

Clouse SD, Sasse JM (1998) Brassinosteroids: essential regulators of plant growth and development. Annu Rev Plant Physiol Plant Mol Biol 49:427-451

Clouse SD, Langford M, McMorris TC (1996) A brassinosteroid-insensitive mutant in Arabidopsis thaliana exhibits multiple defects in growth and development. Plant Physiol 111:671-678

Friedrichsen DM, Joazeiro CAP, Li JM, Hunter T, Chory J (2000) Brassinosteroid-insensitive-1 is a ubiquitously expressed leucine-rich repeat receptor serine/threonine kinase. Plant Physiol 123:1247-1255

Geldner N, Hyman DL, Wang X, Schumacher K, Chory J (2007) Endosomal signaling of plant steroid receptor kinase BRI1. Genes Dev 21:1598-1602

Gendreau E, Traas J, Desnos T, Grandjean O, Caboche M, Höfte H (1997) Cellular basis of hypocotyl growth in Arabidopsis thaliana. Plant Physiol 114:295-305

Goda H, Shimada Y, Asami T, Fujioka S, Yoshida S (2002) Microarray analysis of brassinosteroid-regulated genes in Arabidopsis. Plant Physiol 130:1319-1334

Gou XP, Yin HJ, He K, Du JB, Yi J, Xu SB, Lin HH, Clouse SD, Li $\mathrm{J}$ (2012) Genetic evidence for an indispensable role of somatic embryogenesis kinases in brassinosteroid signaling. PLoS Genet $8(10): 1371$

Hategan L, Godza B, Szekeres M (2011) Regulation of brassinosteroid metabolism. In: Hayat S, Amad A (eds) Brassinosteroids: a plant hormone. Springer, Dordrecht, pp 57-81

Haubrick LL, Torsethaugen G, Assmann SM (2006) Effect of brassinolide, alone or in concert with abscisic acid, on control of stomatal aperture and potassium currents of Vicia faba guard cell protoplasts. Physiol Plant 128:134-143

Huang HY, Jiang WB, Hu YW, Wu P, Zhu JY, Liang WQ, Wang ZY, Lin WH (2013) BR signal influences Arabidopsis ovule and seed number through regulating related genes expression by BZR1. Mol Plant 6:456-469

Jefferson RA (1987) Assaying chimeric genes in plants: the GUS gene fusion system. Plant Mol Biol Rep 5:387-405

Jefferson RA, Kavanagh TA, Bevan MW (1987) GUS fusions: $\beta$-glucuronidase as a sensitive and versatile gene fusion marker in higher plants. EMBO J 6:3901-3907

Kang J, Tang J, Donnelly P, Dengler N (2003) Primary vascular pattern and expression of $A T H B-8$ in shoots of Arabidopsis. New Phytol 158:443-454

Kay SA, Millar AJ, Brandes C, Hall JC (1994) Video imaging of regulated firefly luciferase activity in plants and Drosophila. Promega Notes Mag 49:22-28

Kim TW, Wang ZY (2010) Brassinosteroid signal transduction from receptor kinases to transcription factors. Annu Rev Plant Biol 61:681-704

Kinoshita T, Caño-Delgado A, Seto H, Hiranuma S, Fujioka S, Yoshida S, Chory J (2005) Binding of brassinosteroids to the extracellular domain of plant receptor kinase BRI1. Nature 433:167-171

\begin{tabular}{|llll|}
\hline Journal : Large 425 & Dispatch : 27-1-2014 & Pages : 13 \\
Article No : 2031 & $\square$ LE & $\square$ TYPESET \\
MS Code : PLAA-D-13-00697 & $\square \quad C P$ & $\square$ DISK \\
\hline
\end{tabular}


Koncz C, Martini N, Szabados L, Hrouda M, Brachmair A, Schell J (1994) Specialized vectors for gene tagging and expression studies. In: Gelvin SB, Schilperoort AR (eds) Plant molecular biology manual, B2. Kluwer, Dordecht, pp 1-22

Li J, Chory J (1997) A putative leucine-rich repeat receptor kinase involved in brassinosteroid signal transduction. Cell 90:929-938

Li J, Jin H (2007) Regulation of brassinosteroid signaling. Trends Plant Sci 12:37-41

Li J, Nagpal P, Vitart V, McMorris TC, Chory J (1996) A role for brassinosteroids in light-dependent development of Arabidopsis. Science 272:398-401

Li J, Wen J, Lease KA, Doke JT, Tax FE, Walker JC (2002) BAK1, an Arabidopsis LRR receptor-like protein kinase, interacts with BRI1 and modulates brassinosteroid signaling. Cell 110:213-222

Michael TP, Breton G, Hazen SP, Priest H, Mockler TC, Kay SA, Chory J (2008) A morning-specific phytohormone gene expression program underlying rhythmic plant growth. PLoS Biol 6:e225

Millar AJ, Short SR, Hiratsuka K, Chua N-H, Kay SA (1992) Firefly luciferase as a reporter of regulated gene expression in higher plants. Plant Mol Biol Rep 10:324-337

Mitra A, Choi HK, An G (1989) Structural and functional analyses of Arabidopsis thaliana chlorophyll a/b-binding protein (cab) promoters. Plant Mol Biol 12:169-179

Montoya T, Nomura T, Farrar K, Kaneta T, Yokota T, Bishop GJ (2002) Cloning of the tomato Curl3 gene highlights the putative dual role of the leucine-rich repeat receptor kinase tBRI1/SR160 in plant steroid hormone and peptide hormone signaling. Plant Cell 14:3163-3176

Montoya T, Nomura T, Yokota T, Farrar K, Harrison K, Jones JGD, Kaneta T, Kamiya Y, Szekeres M, Bishop GJ (2005) Patterns of Dwarf expression and brassinosteroid accumulation in tomato reveal the importance of brassinosteroid synthesis during fruit development. Plant J 42:262-269

Müssig C, Shin GH, Altmann T (2003) Brassinosteroids promote root growth in Arabidopsis. Plant Physiol 133:1261-1271

Nam KH, Li J (2002) BRI1/BAK1, a receptor kinase pair mediating brassinosteroid signaling. Cell 110:203-212

Nemhauser JL, Mockler TC, Chory J (2004) Interdependency of brassinosteroid and auxin signaling in Arabidopsis. PLoS Biol 2:e258

Nomura T, Kushiro T, Yokota T, Kamiya Y, Bishop GJ, Yamaguchi S (2005) The last reaction producing brassinolide is catalyzed by cytochrome P450s, CYP85A3 in tomato and CYP85A2 in Arabidopsis. J Biol Chem 280:17873-17879

Nomura T, Ueno M, Yamada Y, Takatsuto S, Takeuchi Y, Yokota T (2007) Roles of brassinosteroids and related mRNAs in pea seed growth and germination. Plant Physiol 143:1680-1688

Roux M, Schwessinger B, Albrecht C, Chinchilla D, Jones A, Holton N, Malinovsky FG, Tör M, de Vries S, Zipfel C (2011) The Arabidopsis leucine-rich repeat receptor-like kinases BAK1/SERK3 and BKK1/SERK4 are required for innate immunity to hemibiotrophic and biotrophic pathogens. Plant Cell 23:2440-2455

Russinova E, Borst JW, Kwaaitaal M, Cano-Delgado A, Yin Y, Chory J, de Vries SC (2004) Heterodimerization and endocytosis of Arabidopsis brassinosteroid receptors BRI1 and AtSERK3 (BAK1). Plant Cell 16:3216-3229

Sakamoto T, Morinaka Y, Inukai Y, Kitano H, Fujioka S (2013) Auxin signal transcription factor regulates expression of brassinosteroid receptor gene in rice. Plant J 73:676-688

Savaldi-Goldstein S, Peto C, Chory J (2007) The epidermis both drives and restricts plant shoot growth. Nature 446:199-202

Shimada Y, Goda H, Nakamura A, Takatsuto S, Fujioka S, Yoshida S (2003) Organ-specific expression of brassinosteroid-biosynthetic genes and distribution of endogenous brassinosteroids in Arabidopsis. Plant Physiol 131:287-297

Symons GM, Reid JB (2004) Brassinosteroids do not undergo longdistance transport in pea. Implications for the regulation of endogenous brassinosteroid levels. Plant Physiol 135:2196-2206

Symons GM, Davies C, Shavrukov Y, Dry IB, Reid JB, Thomas MR (2006) Grapes on steroids. Brassinosteroids are involved in grape berry ripening. Plant Physiol 140:150-158

Symons GM, Chua YJ, Ross JJ, Quittenden LJ, Davies NW, Reid JB (2012) Hormonal changes during non-climacteric ripening in strawberry. J Exp Bot 63:4741-4750

Szekeres M, Németh K, Koncz-Kálmán Z, Mathur J, Kauschmann A, Altmann T, Rédei G, Nagy F, Schell J, Koncz C (1996) Brassinosteroids rescue the deficiency of CYP90, a cytochrome P450, controlling cell elongation and de-etiolation in Arabidopsis. Cell 85:171-182

Tanaka K, Asami T, Yoshida S, Nakamura Y, Matsuo T, Okamoto S (2005) Brassinosteroid homeostasis in Arabidopsis is ensured by feedback expressions of multiple genes involved in its metabolism. Plant Physiol 138:1117-1125

Truernit E, Sauer N (1995) The promoter of the Arabidopsis thaliana SUC2 sucrose- $\mathrm{H}^{+}$symporter gene directs expression of $\beta$-glucuronidase to the phloem: evidence for phloem loading and unloading by SUC2. Planta 196:564-570

Turk EM, Fujioka S, Seto H, Shimada Y, Takatsuto S, Yoshida S, Denzel MA, Torres QI, Neff MM (2003) CYP72B1 inactivates brassinosteroid hormones: an intersection between photomorphogenesis and plant steroid signal transduction. Plant Physiol 133:1643-1653

van Esse GW, Westphal AH, Surendran RP, Albrecht C, van Veen B, Borst JW, de Vries SC (2011) Quantification of the BRI1 receptor in planta. Plant Physiol 156:1691-1700

Vert G, Welcher CL, Chory J, Nemhauser JL (2008) Integration of auxin and brassinosteroid pathways by auxin response factor 2 . Proc Natl Acad Sci USA 105:9829-9834

Viczián A, Kircher S (2010) Luciferase and green fluorescent protein reporter genes as tools to determine protein abundance and intracellular dynamics. Methods Mol Biol 555:293-312

Wang X, Chory J (2006) Brassinosteroids regulate dissociation of BKI1, a negative regulator of BRI1, from the plasma membrane. Science 313:1118-1122

Wang ZY, Seto H, Fujioka S, Yoshida S, Chory J (2001) BRI1 is a critical component of a plasma-membrane receptor for plant steroids. Nature 410:380-383

Wang X, Kota U, He K, Blackburn K, Li J, Goshe MB, Huber SC, Clouse SD (2008) Sequential transphosphorylation of the BRI1/BAK1 receptor kinase complex impacts early events in brassinosteroid signaling. Dev Cell 15:220-235

Wang X, Zhang J, Yuan M, Ehrhardt DW, Wang Z, Mao T (2012a) Arabidopsis MICROTUBULE DESTABILIZING PROTEIN 40 is involved in brassinosteroid regulation of hypocotyl elongation. Plant Cell 24:4012-4025

Wang ZY, Bai MY, Oh E, Zhu JY (2012b) Brassinosteroid signaling network and regulation of photomorphogenesis. Annu Rev Genet 46:701-724

Yang XH, Xu ZH, Xue HW (2005) Arabidopsis membrane steroidbinding protein 1 is involved in inhibition of cell elongation. Plant Cell 17:116-131

Zhao B, Li J (2012) Regulation of brassinosteroid biosynthesis and inactivation. J Integr Plant Biol 54:746-759

Zhou A, Wang H, Walker JC, Li J (2004) BRL1, a leucine-rich repeat receptor-like protein kinase, is functionally redundant with BRI1 in regulating Arabidopsis brassinosteroid signaling. Plant J 40:399-409 